\title{
Providing water in areas with unsustainable usage
}

\section{Thomas F. Wiener}

The IEEE Water for the World project is bringing fresh water to needy people by analyzing remote sensing imagery and other Earth observations.

Fresh water is a fundamental requirement for humanity's wellbeing. However, more than one billion people today are without safe drinking water. The United Nations (UN) estimates $20 \%$ of the world's population lives in areas with unsustainable water use and predicts that by 2025 two-thirds of the population will live in water-stressed conditions.

Water for the World, a program to bring fresh water to those who do not have it, is supported by the US National Aeronautics and Space Administration and the IEEE Foundation. The program is part of IEEE's collaboration with Group on Earth Observations (GEO), a voluntary partnership of governments and international organizations that provides a framework for developing new projects and coordinating strategies and investments. GEO also is assembling a Global Earth Observation System of Systems (GEOSS), a flexible global network linking existing and planned observing systems around the world, to allow decisionmakers and users access to an vast range of information. This data and these tools are central to accomplishing Water for the World's mission.

Water for the World is being implemented in three phases. ${ }^{1}$ The first phase produced a 'vision' that identified realizable activities to deliver adequate clean water to much of the world. It also described suitable pilot projects to demonstrate the utility of the vision's proposals. The second phase outlines 15 pilot projects, three of which have been started. The final phase will focus on institutionalizing an accepted and supported international plan to provide a Water for the World project that can be owned and directed by users and beneficiaries.

The Water for the World leadership held several global meetings to identify the 15 key phase-two projects, which-when successfully implemented-are expected to make significant impact on solving global water issues. The three active pilot projects
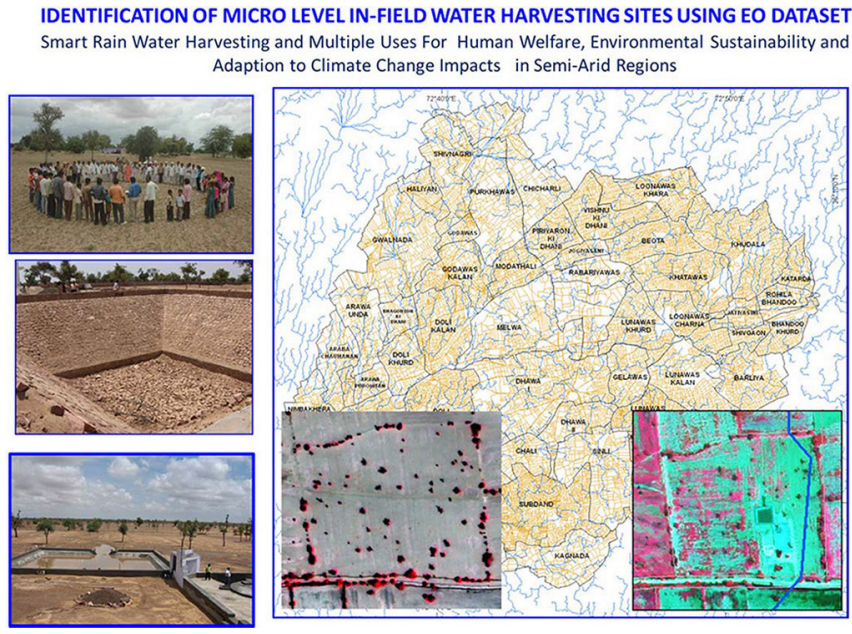

Figure 1. Identification of micro level in-field water harvesting sites in northwestern India using the Earth observation dataset.

focus on India, Nicaragua, and Ghana. We will execute others one by one, as we acquire funding.

Our first project is based in semi-arid northwestern India, where storms and the uneven distribution of rainfall in time and space limit water's availability for agriculture and drinking. The project's main goal is to replace water harvesting from unsafe village ponds with rain captured in cisterns and establish a system by which the water can be managed to provide sufficient supplies throughout the year.

Figure 1 shows the digital elevation model of micro-level drains in agriculture fields in a cluster of 50 villages along with cadastral boundaries, which was obtained using Cartosat-1 stereo image data. Photographs of the pilot site before and after the harvesting structure, made by the residents of the village, are also shown. The project is a collaboration between the local villagers and is technically supported by the Indian Space Research Organization, Marwar Geo-Cultural Society (MGCS) non-governmental organization, and IEEE. 
The initial demonstration was based on a farm of 3 hectares with a five-person family owning five cattle. The cistern was built by MGCS. After the first year, the improved water supply resulted in a trebling of agricultural productivity. Additionally, the quality and availability of drinking water improved. The project is ongoing, with the goal of expanding to more participating farms and realizing similar productivity increases. We are using advanced geospatial techniques and methods to pinpoint areas of low and high water productivity in this semi-arid environment. We also use these techniques to suggest methods for improving crop water productivity in the cluster of villages. Furthermore, we have established a pilot regional-training and capacity-building facility to use as a base for analysis and expansion. A similar program is underway in Burkina Faso, which is
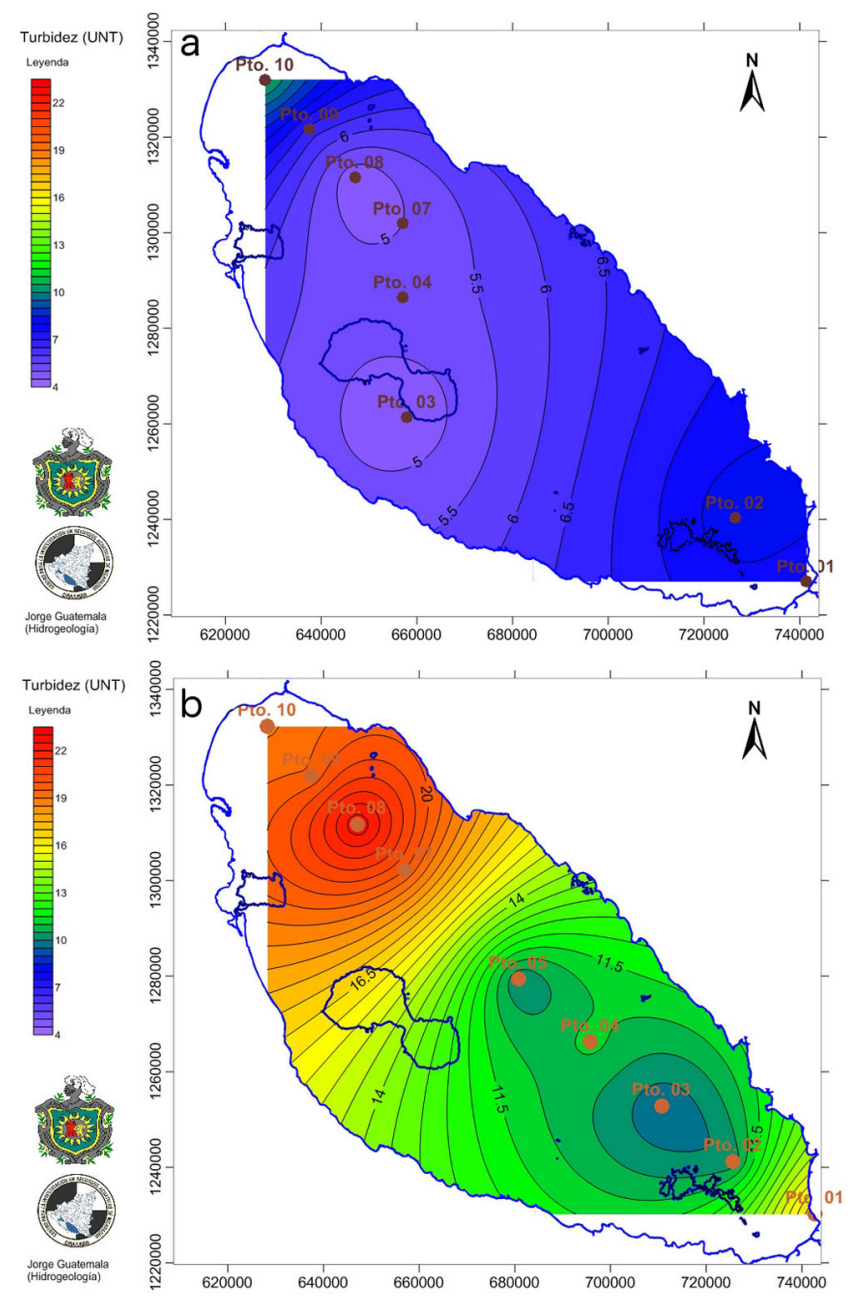

Figure 2. Seasonal turbidity in Lake Nicaragua showing sample points in (a) December 2011 and (b) March 2012. using remote-sensing data from a European satellite for further environmental analyses.

The second project, which uses Lake Nicaragua as a demonstration site, is developing a satellite-based water quality monitoring system. Nicaragua as a nation has limited resources for water quality monitoring, so the satellite system is a potentially cost-effective method. The project-part of GEOSS in the American hemisphere-is being conducted by the Nicaraguan Research Center for Aquatic Resources of the National Autonomous University of Nicaragua and the Wisconsin Department of Natural Resources and is specifically looking at the level of particulates in the lake. For example, two medium-resolution imaging spectrometer images were acquired from the European Space Agency. Hyperspectral reflectance measurements were taken from a boat in situ on corresponding dates to determine spectral absorption coefficients of particles, dissolved material, and phytoplankton in the lake. Images of total suspended solids and chlorophyll from December 2011 and March 2012 showed the effects on water quality of changing meteorological conditions, changing water volumes between periods, water depth, and riverine inputs with nutrient content. Figure 2 shows the sampling points and the seasonal variation.

Finally, the third pilot project underway uses the Ghana Weija Reservoir management project as the pilot site. This project will provide a spatial planning information system with cartographic visualization of the urban and small-town piped systems. This information system will provide monitoring of the current situation of the reservoirs and piping systems and planning tools for modernization. The local government has accepted the project and supports to a limited extent the initial surveys and coordination. The team is in place awaiting further funding.

In the future, we need to find additional funding for the vision document's pilot projects. Our goal is to make progress using existing and innovative technologies that are easy to implement and scalable across a broad spectrum of the global population.

\section{Author Information}

\section{Thomas F. Wiener}

IEEE Committee on Earth Observation

Alexandria, VA 
Thomas F. Wiener, an aerospace engineer with 50 years of experience in high technology research and development, was a program manager at the Defense Advanced Research Projects Agency. In the US Navy, he commanded the nuclear attack submarine USS JACK. He sings baritone in Seven Thirty-four, a barbershop quartet.

\section{References}

1. T. F. Wiener, P. S. Thenkabail, J. Montgomery, J. Pearlman, R. Lawford, and M. A. Hanjra, 2010. A blueprint for Water for the World: Pathway to a blue revolution. IEEE. http://www.ieee-earth.org/wp-content/uploads/2009/10/final-ABlueprint-for-Water-for-the-World-November-2010.pdf. Accessed 26 March 2013. 